INVESTIGACIONES

de HISTORIA ECONÓMICA

2006, otoño, número 6. Pp. 137 a 168

\title{
Relaciones interempresariales y consejeros comunes en la banca española del siglo $X X$
}

\author{
Inter-firm relationships and interlocking directorates \\ in twentieth century Spanish banking
}

\author{
JAVIER PUEYO SÁNCHEZ \\ Universitat Pompeu Fabra, Barcelona
}

\begin{abstract}
RESUMEN
La historiografía española sobre la banca afirma que los grandes bancos han actuado durante el siglo XX como si de un monopolio se tratase. Uno de los mecanismos de coordinación habría sido una red de consejeros comunes que comprendería a la mayor parte de las entidades financieras. En este artículo se reconstruyen las redes de consejeros comunes en la banca española del siglo XX con la intención de comprobar la estabilidad de estas relaciones. Los resultados muestran que no existió ninguna red lo suficientemente duradera que abarcara al conjunto de los grandes bancos. En consecuencia, debe descartarse que los consejeros comunes actuaran como coordinadores de un hipotético monopolio bancario sostenido durante varias décadas. El examen de la literatura existente

sobre la historia de los bancos españoles apunta a otras opciones posibles, como, por ejemplo, la búsqueda de socios para acceder a otros mercados geográficos, para participar en operaciones sindicadas o como candidatos para futuras absorciones.
\end{abstract}

PALABRAS CLAVE: Monopolización, Consejeros comunes, Banca española, Siglo XX

Códigos JEL: L12, L14, N24

\section{ABSTRACT}

Spanish banking historiography asserts that the largest banks performed over the twentieth century as though they constituted a monopoly. One of its main coordination schemes would have been a network of interlocking bank directors that would include most of the financial firms. Evidence available for the 1920s and 1960s seems to confirm the veracity of this hypothesis. In this paper, more systematic evidence has been collected to cover the whole twentieth century. The aim is to check whether these networks have persisted over the entire alleged period or they are by-products of particular events. Our results show that no general network remained for more than a decade. Therefore, it should be dismissed that interlocking directorates worked as coordination device of the so-called banking cartel. A summary review of the literature about the history of Spanish banks reveals that other possibilities are feasible.

KEYWORDS: Monopolization strategies, Interlocking directorates, Spanish banking, 20th Century

JEL Codes: L12, L14, N24 


\section{Introducción 1}

U no de los tópicos de la historia bancaria española afirma que han existido grupos de bancos vinculados por consejeros comunes, personas que ocupaban simultáneamente puestos en los consejos de administración de varias entidades. La función de estos consejeros habría sido la de coordinar las estrategias colusivas de las entidades con objeto de rebajar o anular la competencia, configurar los mercados financieros a su conveniencia y obtener las rentas ligadas al ejercicio del monopolio. La base empírica de esta tesis se encuentra en sendos estudios que reconstruyeron tales redes para las décadas de 1920 y 1960. Se estableció para ambos periodos la existencia de una trama muy densa, que relacionaba prácticamente a la totalidad de los grandes bancos. Este hallazgo fue considerado por los autores citados como una prueba favorable a la tesis de la colusión bancaria, que se habría estado ejerciendo ininterrumpidamente desde, al menos, los años de la I Guerra Mundial $^{2}$.

Esta explicación forma parte de una tesis más general que atribuye a los grandes bancos españoles una capacidad de influencia tal que el sector financiero español durante el siglo XX ha de analizarse en términos de cártel o monopolio. Según la misma, el grupo de los grandes bancos habría acordado los precios y características del negocio bancario para el conjunto de la banca, acudiendo al apoyo del Estado cuando le hubiera sido preciso ${ }^{3}$. Esta tesis fue desarrollada en círculos vinculados al falangismo de corte regeneracionista, que denunciaban la infiltración del gran capital en la Administración franquista y, posteriormente, fue utilizada por grupos de oposición al Régimen para denunciar las bases oligárquicas del mismo ${ }^{4}$. La idea del monopolio se estableció a la vista de las relaciones opacas entre la banca y los gobiernos franquistas, interpretadas con ayuda de la hipótesis del capital financiero de Hilferding y avaladas por una serie de trabajos empíricos que aportaron evidencia acerca de la elevada concentración económica del sector y la existencia de estrechas conexiones entre las direcciones de los bancos a través de consejeros comunes y una serie de organismos corporativos (Consejo Superior Bancario) y semiestatales (bancos oficia-

[Fecha de recepción del original, febrero de 2005. Versión definitiva, mayo de 2006]

1 Una primera versión de este texto se presentó en el X Simposio de Historia Económica, Universidad Autónoma de Barcelona, 27-29 de enero de 2005. Agradezco al relator de la sesión, Matthias Kipping, y a los asistentes a la misma sus comentarios, así como a los tres evaluadores anónimos de Investigaciones de Historia Económica. Los errores que permanezcan corresponden al autor.

Véanse Roldán y García Delgado (1973), y Muñoz (1969).

Un estudio sistemático del origen y desarrollo de esta tesis se encuentra en Pueyo (en prensa).

Para la filiación falangista, véase AA. VV. (1954). La relación con la oposición de izquierdas puede verse en los dos números extraordinarios de Cuadernos para el Diálogo, publicados en 1968. Los materiales más relevantes de esta última referencia sirvieron para componer Muñoz (1969). 
les). A pesar de su origen claramente político, la tesis del poder de la banca fue asumida completamente por la historiografía española contemporánea sin que haya sido sometida a investigaciones rigurosas hasta muy recientemente ${ }^{5}$.

El objetivo de este artículo consiste en contrastar una de las hipótesis auxiliares de esta tesis general: la que asegura que la coordinación oligopolista se realizó a través de una serie de personas que ocuparon simultáneamente puestos en varios consejos de administración de entidades bancarias. Esta hipótesis da por supuesto que las estrategias de las entidades financieras se decidían en los consejos de administración, cuyos componentes - fueran o no directores ejecutivos- tendrían plena capacidad de decisión. La función de los consejeros comunes habría consistido en vigilar el cumplimiento de unos supuestos acuerdos colusivos y en coordinar las actuaciones de las distintas entidades cuando hubiera sido preciso. Esta coordinación oligopolista se habría iniciado con la promulgación de la primera Ley de Ordenación Bancaria en 1921, sobreviviría a la Guerra Civil, se habría visto fortalecida gracias a la regulación del statu quo franquista, y no desaparecería hasta las décadas de 1970 ó 1980. Los autores partidarios de esta interpretación indicaron, también, el método para aportar pruebas empíricas: el cruce de las listas de consejeros para identificar a los que fueran comunes a varias entidades. A partir de estas relaciones, se observaría que todos los grandes bancos, y buena parte de los de menor tamaño, se encontraban incluidos en una misma trama. Esta red de consejeros fue empíricamente reconstruida con información correspondiente a las décadas de los veinte y de los sesenta, pero no se llevó a cabo ningún trabajo que estableciera si dicha trama se mantuvo en las fechas intermedias. En consecuencia, se supuso implícitamente que la red se conservó entre ambas fechas, lo que probaría la solidez de la colusión.

En este artículo, tras un resumen del debate historiográfico sobre los consejeros comunes en la banca española, en el segundo apartado, se presenta nueva evidencia empírica, al respecto, en el tercero. Se han cruzado los directorios de una muestra muy amplia y representativa de bancos españoles para los años 1915, 1925, 1934 y 1946, y de la totalidad de las entidades bancarias para 1975, 1980 y 1985. Los resultados obtenidos se han comparado con los estudios citados en la nota 2 (1921, 1961 y 1966-1967), con objeto de comprobar la persistencia de las redes de consejeros comunes. Nuestros resultados, que se comentan en el cuarto apartado, no son favorables a la tesis tradicional, por lo que, en el quinto, se apuntan causas alternativas que expliquen la presencia de estas redes. Un apartado de conclusiones cierra el trabajo. 


\section{El debate historiográfico}

En la historiografía española se considera que la banca estuvo sometida a una intensa cartelización bajo el liderazgo de los grandes bancos durante prácticamente todo el siglo XX6 . De hecho, suele utilizarse el término "monopolio" para caracterizar el tipo de relaciones establecidas entre las entidades financieras y destacar, así, la situación de colusión permanente existente en los mercados financieros españoles desde el final de la I Guerra Mundial hasta las últimas décadas del siglo XX7. El origen de esta interpretación del comportamiento de la banca española se encuentra en una serie de trabajos realizados en los años cuarenta y cincuenta, en los que se analizó la estructura de mercado de una serie de sectores en busca de circunstancias que favorecieran los acuerdos restrictivos de la competencia ${ }^{8}$. De acuerdo con los conceptos de la época y las fuentes de información disponibles, más bien parcas, se estableció una lista de industrias cuyo carácter oligopolista parecía evidente. Los análisis comprendieron el cálculo de índices de concentración y evaluaciones de la altura de las barreras de entrada a partir del número anual de nuevas empresas, y se intentó, además, establecer las conexiones entre empresas mediante el método de los consejeros comunes.

La banca se encontró, desde el principio, en la lista de las industrias sospechosas de estar configuradas como un oligopolio colusivo. Los estudios citados establecieron que la concentración en este sector era muy elevada, el acceso al sector se hallaba totalmente cerrado debido a la regulación del statu quo y los grandes bancos se encontraban estrechamente vinculados entre sí, a través de una serie de personajes que ocupaban simultáneamente puestos en varios consejos de administración, lo que para estos autores suponía evidencia clara de que los bancos en cuestión coordinaban sus actuaciones. Adicionalmente, el Consejo Superior Bancario y los consejos de administración del Banco de España y del resto de bancos oficiales servían también de foros donde discutir y coordinar las estrategias del conjunto de la banca. A partir de esta evidencia de concentración elevada, industria cerrada y con mecanismos de coordinación interempresarial, se estableció la idea de que la banca española constituía un oligopolio colusivo perfecto, que contaba con el apoyo del Estado. El inicio de este cártel —-monopolio fue el término que se utilizó en su día — se dató en los años veinte, década en que se promulgó la primera Ley de Ordenación Bancaria y se crearon el Consejo Superior Bancario y los bancos oficiales. También habría

$6 \quad$ Véanse, por ejemplo, Tortella (1995) o García Delgado y Jiménez (1999).

7 Se suele citar el año 1989 como el principio del fin de esta situación de colusión estable, a raíz de la campaña de promoción lanzada por el Banco de Santander de un activo financiero nuevo (las llamadas "supercuentas") con el objetivo explícito de captar clientes de otras entidades.

8 Véanse De la Sierra (1951), Muñoz Linares (1952) y (1955), Tamames (1961) y Muñoz (1969). 
sido entonces cuando se habría formado la red de consejeros comunes. Efectivamente, el trabajo firmado por Santiago Roldán y José Luis García Delgado estableció la existencia de esta red ya en 1921, cuya permanencia en 1966-1967 había sido confirmada unos años antes por Juan Muñoz 9 . De esta manera, se habría corroborado la tesis de la colusión permanente en el seno de la banca española desde los años veinte hasta, al menos, los sesenta.

Recientemente, se ha empezado a cuestionar la tesis de la monopolización de la banca. Se ha comprobado que la concentración económica ni fue siempre tan elevada como se presumió, ni destacaba especialmente en el contexto internacional ${ }^{10}$. Se ha verificado la existencia de acuerdos entre los bancos durante el franquismo, pero también se ha comprobado su corta duración y la laxitud con que fueron respetados por sus firmantes ${ }^{11}$. Igualmente, la legislación aparentemente restrictiva del statu quo no siempre constituyó un obstáculo para la rivalidad entre las entidades financieras, dado que el Ministerio de Hacienda no siempre se mostró dispuesto a hacer cumplir la ley de modo estricto ${ }^{12}$. El panorama que surge de estas investigaciones recientes apunta hacia la configuración del sistema bancario español del siglo XX como un oligopolio típico: un mercado con presencia de grandes entidades, susceptibles de actuar colusivamente, pero con dificultades para estabilizar los acuerdos y, en consecuencia, con períodos alternos de rivalidad y colusión. El carácter de oligopolio viene dado por la presencia de unos pocos grandes bancos (entre cinco y siete, según la época) que actuaban en la mayor parte del país a través de sus redes de sucursales. No obstante, también debe destacarse la presencia de un gran número de bancos medianos y pequeños, algunos de ellos con una fuerte implantación regional. A éstos han de sumarse las cajas de ahorros, que a medida que avanzaba el siglo iban convirtiéndose en bancos propiamente dichos, dejando de lado paulatinamente su carácter de entidades benéficas ${ }^{13}$. El gran número de entidades y sus muy diversas características y estrategias habrían constituido por sí solos obstáculos a la colusión, pero, además, la diferenciación de producto y los problemas de información que caracterizan el negocio bancario configuran un sector con dificultades especiales para mantener pactos restrictivos de la competencia ${ }^{14}$. En esta situación, los bancos

9 Roldán y García Delgado (1973), vol. 2, pp. 264-269; Muñoz (1969), capítulo 4.

10 Véanse Fanjul y Maravall (1982) y (1985), y Pueyo (2003).

11 Véanse García Ruiz (2002) y García Ruiz y Tortella (2003).

12 Véase Pons (1999), (2001) y (2002). En Faus (2001) se pueden encontrar algunas indicaciones acerca de las artimañas utilizadas durante todo el franquismo para eludir la regulación, como, por ejemplo, los extratipos o las sucursales encubiertas bajo el título de corresponsales exclusivos.

13 Véanse las ponencias presentadas en la sesión B8 del VIII Congreso de la Asociación Española de Historia Económica (Santiago de Compostela, 13-16 septiembre de 2006), dedicada a las cajas de ahorros.

14 Acerca de la caracterización que se aplica actualmente a la industria bancaria y las dificultades para establecer el tipo de estructura de mercado predominante, véanse Dell'Ariccia (2001) y Shaffer (2004). 
españoles habrían tenido un claro incentivo para coludir y rebajar la competencia: las rentas monopolistas a extraer de un mercado cartelizado. Pero, como suele suceder en este tipo de estructura de mercado, una vez establecido un acuerdo, cada entidad se enfrentaría al incentivo que representaban los beneficios adicionales que podría obtener si incumpliese los pactos, en la medida en que fuera posible ocultar la infracción. Dada la facilidad para diferenciar los productos financieros y los problemas de información, habría resultado complicado controlar el cumplimiento de los acuerdos.

A este respecto, el apoyo del Estado y sus poderes coercitivos hubieran sido una gran ayuda para consolidar cualquier hipotética colusión, como sucedió en otros países $^{15}$. Esto introduce un nuevo agente, el Estado, y en consecuencia, un conjunto adicional de objetivos y prácticas que se ha de relacionar con los objetivos y actuaciones empresariales. Poco se sabe de la actuación del Estado español hacia la banca antes de la Guerra Civil, y tampoco demasiado acerca de la política del Régimen franquista. Antes del conflicto aparecieron las primeras regulaciones específicamente bancarias, que incluyeron algunas medidas que, en principio, restringirían la rivalidad en el sector (regulación de tipos de interés, autorización administrativa para entrar en el mercado o abrir sucursales), pero que podrían deberse tanto a la captura del regulador, como constituir un método para garantizar la estabilidad del sistema, a falta de un prestamista de última instancia ${ }^{16}$. Después de la guerra, el régimen franquista facilitó una de las condiciones ideales para la colusión al cerrar totalmente el mercado, pero, por otro lado, aparentemente se mostró más interesado en controlar la movilidad dentro del sector y obtener financiación para los gastos públicos, que en apoyar los acuerdos colusivos privados ${ }^{17}$.

Por otro lado, la hipótesis tradicional se asienta en un supuesto implícito muy cuestionado en la literatura empresarial. La aplicación de la técnica de análisis en cuestión de consejeros (interlocking directorates) se sustenta en el supuesto de que los miembros de los consejos de administración posean una capacidad de influencia

15 El ejemplo mejor estudiado es el de Gran Bretaña, donde el Estado colaboró con los grandes bancos privados para hacer respetar los acuerdos restrictivos de la competencia que éstos habían acordado (Capie y Billings, 2004). El gobierno británico perseguiría sus propios objetivos con este apoyo, que consistían en asegurar la estabilidad del sistema financiero, promocionar la City como centro financiero internacional, facilitar la gestión de la política monetaria y allegar recursos financieros para sus políticas de gasto (Collins, 1988).

16 Esta última idea la sostiene explícitamente Faus (2001), pp. 115-118.

17 Según Poveda (1980), el interés principal del Estado franquista consistió en utilizar los recursos de la banca para financiar sus políticas, una vez asegurada la estabilidad del sistema gracias a la aplicación del statu quo. García Ruiz (2002) explica las reticencias del Estado para apoyar los pactos acordados entre los bancos privados. Un análisis más extenso de la regulación de la banca entre 1921 y 1974 se puede consultar en Pueyo (en prensa), capítulo 4. 
efectiva en el funcionamiento de las empresas. De esta manera, aquéllos que estuvieran presentes en los consejos de varias empresas del mismo sector estarían capacitados para coordinar las actuaciones de las mismas o, al menos, para transmitir información relevante para esta finalidad. La hipótesis del monopolio de la banca en España — como demuestran las citas contenidas en el libro de Juan Muñoz (1969)— se sostiene explícitamente en planteamientos marxistas, según los cuales la economía capitalista tiende a la concentración del poder económico en manos de una oligarquía, cuyos representantes supremos serían los grandes banqueros. Los miembros de esta oligarquía se sentarían en los consejos de administración de bancos y grandes empresas, coordinarían sus actividades y restringirían la competencia en los mercados, lo que acabaría monopolizando el conjunto de las economías capitalistas desarrolladas ${ }^{18}$.

Sin embargo, la literatura empresarial suele mostrase escéptica en este punto. Se considera que el control de la empresa recae en los directores ejecutivos, sean o no miembros de los consejos de administración, ya que son ellos los que controlan la información generada por la empresa y sus recursos materiales y humanos. En consecuencia, la función del consejo de administración se encontraría muy limitada porque su fuente principal de información serían los mismos directivos, cuya actuación se supone que deben controlar en nombre de los accionistas. Se ha llegado a afirmar que la composición del consejo serviría únicamente para reforzar el prestigio de los directores ejecutivos de cara al exterior, al sentar en el consejo de su empresa a personas de prominencia social o económica. Otra aproximación menos extrema considera que las relaciones mediante consejeros comunes responderían al comportamiento optimizador de las empresas. En tal caso, no sería más que uno de los mecanismos que éstas emplearían para alcanzar sus objetivos, que, obviamente, pueden incluir la colusión, pero también pueden servir para otros propósitos ${ }^{19}$.

En el campo de la historia económica, la hipótesis de la capacidad de actuación de los consejeros comunes y la técnica asociada (interlocking directorates) se ha aplicado en el contexto de las teorías de Gerschenkron acerca de la función de los bancos universales en la industrialización de algunos países europeos. Los consejeros comunes habrían sido un mecanismo utilizado para establecer relaciones a largo plazo entre empresas industriales y bancos universales, suponiéndose además que la

18 El origen de esta teoría se encuentra en Hilferding (1985 [1910]).

19 No existen conclusiones definitivas acerca de cuál es la capacidad de influencia de los consejeros sobre los directores ejecutivos y, en consecuencia, sobre la estrategia y la gestión de las empresas (HermalinWeisbach, 2003). Mace (1986) presenta testimonios de directivos y consejeros de empresas norteamericanas que le permiten sostener la irrelevancia de los consejos en el proceso de toma de decisiones. Por su parte, Termes (1991) niega que los consejos de administración participasen en la gestión de los bancos españoles. 
hegemonía correspondería a las entidades financieras. Algunos trabajos recientes han cuestionado la validez de esta hipótesis, ante la falta de suficiente evidencia empírica ${ }^{20}$. Estos autores concluyen que los consejos de administración no tienen el mismo papel en todas las empresas y que los motivos de que una misma persona aparezca en los consejos de varias empresas pueden ser muy diversos, por lo que no cabe llegar a conclusiones generales sin un estudio mínimamente detallado de cada caso.

En consecuencia, existen varias formas de interpretar las relaciones entre empresas a través de sus consejeros comunes, que van desde la irrelevancia de este tipo de vínculo hasta identificarlo como un elemento fundamental para la coordinación monopolista, pasando por su consideración como uno más de los instrumentos de que disponen las empresas para alcanzar sus objetivos, sin que uno de éstos sea necesariamente la colusión. Si el nombramiento de consejeros nada tuviera que ver con las líneas maestras de actuación de las empresas, entonces la técnica de identificar consejeros comunes conduciría a conclusiones erróneas acerca de las relaciones interempresariales. Sin embargo, aunque dichos consejeros no tuvieran una participación efectiva en la toma de decisiones, la técnica de los consejeros comunes sería útil para establecer dichas relaciones si la composición de los consejos de administración derivase indirectamente de alguna de las actuaciones de las empresas. Por ejemplo, el intercambio de consejeros suele acompañar a la adquisición de paquetes de acciones de una empresa o al establecimiento de pactos de cualquier tipo (también colusivos). El problema estriba en identificar la causa de la comunidad de consejeros, lo que exige una investigación detallada de las directrices estratégicas de las empresas implicadas, entre las cuales la colusión es sólo una posibilidad entre otras. En este contexto, la técnica en cuestión (interlocking directorates) serviría solamente como un primer paso para seleccionar un grupo de empresas en el que centrar la investigación.

\section{Los consejeros comunes en la banca española del siglo XX}

A pesar de la falta de rigurosidad de la hipótesis y de la escasez de evidencia empírica, la historiografía española ha aceptado dentro de sus planteamientos que los consejeros comunes de la banca actuaron como un mecanismo de coordinación de

20 Véanse Fohlin (1999) y Tomka (2001). Guinnane (2002) rebaja el papel de los bancos universales alemanes en el proceso de industrialización, tanto al situarlos en el contexto del sistema financiero en su conjunto, como al examinar su origen y evolución histórica. 
acciones colusivas. De esta manera, aparece como la tesis de partida en cualquier análisis acerca de la coordinación oligopolista en la banca española del siglo XX. En este apartado se presentan los resultados de una investigación dirigida a reunir evidencia empírica sistemática acerca de la existencia de ese tipo de redes, formadas mediante consejeros comunes ${ }^{21}$. El objetivo estriba en comprobar en qué medida la evidencia empírica establecida a partir del método propuesto por los defensores de la hipótesis resulta coherente con sus postulados explicativos. Para ello, se han reconstruido las redes bancarias formadas por consejeros comunes siguiendo el método propuesto por los autores mencionados y utilizando sus mismas fuentes, pero para un número mayor de años, de tal manera que se cubra la práctica totalidad del siglo XX.

Partimos de los trabajos citados de Muñoz, Roldán y García Delgado que establecieron las redes de consejeros comunes en 1921, 1961 y 1966-196722. Para contrastar la permanencia de dichas redes se ha procedido a seleccionar una serie de años anteriores (1915), intermedios (1925, 1934 y 1946) y posteriores $(1975,1980,1985$ y 1990) a dichas fechas. Se ha acudido al mismo tipo de fuentes empleado por dichos autores: el Anuario Financiero y de Valores Mobiliarios, año I (1916), para establecer los directorios de consejeros bancarios de 1915, y los Anuarios Financieros y de Sociedades Anónimas de los años 1926, 1935 y 1947, para fijar los directorios correspondientes a 1925, 1934 y 1946. Lamentablemente, estos Anuarios no tenían cobertura universal. Tan sólo publicaban la información de aquellas entidades que voluntariamente decidían enviarla a los editores. Aún así, los Anuarios incluyen todos los grandes bancos y buena parte de los medianos y pequeños. Para 1975, 1980, 1985 y 1990 se ha dispuesto de una cobertura universal, gracias a que los Anuarios Estadísticos de la Banca Privada, editados por la Asociación Española de Banca (AEB) desde los años setenta, comprenden la totalidad de los miembros de los consejos de administración de los bancos privados españoles.

La fecha inicial se ha fijado en 1915, para situarnos antes del impacto ejercido por la I Guerra Mundial, con la esperanza de que los grupos que encontremos sean representativos de la España de la Restauración. A continuación, se han considerado los años 1925 y 1934 para comprobar si las redes bancarias detectadas por Roldán y García Delgado para 1921 sobrevivieron a los cambios políticos y económicos del

21 En los apéndices se presentan las agrupaciones detectadas y sus relaciones. Los detalles del método utilizado, los listados completos de consejeros comunes y el número de enlaces entre los bancos que formaban cada agrupación pueden consultarse en Pueyo (2006).

22 Véanse Roldán y García Delgado (1973), vol. 2, pp. 264-269, y Muñoz (1969), capítulo 4. Otros trabajos del mismo tipo, cuyas agrupaciones pueden compararse con las presentadas en este texto, son: De la Sierra (1951) para 1949; Tamames (1961) para 1958; la segunda edición de 1966 de esta misma referencia para 1963, y Tamames (1977) para 1975. 
período de entreguerras. Como fecha representativa de la posguerra se ha elegido 1946, cuando ya se habían normalizado las operaciones bancarias y estaba a punto de consolidarse definitivamente el entramado legal del franquismo con la Ley de Ordenación Bancaria de ese mismo año. La comparación con los grupos existentes antes de la Guerra Civil permitiría apreciar el impacto del conflicto y de la inmediata posguerra. El statu quo que caracterizó la regulación bancaria del franquismo debería dejar sus huellas en los grupos detectados en su día por Juan Muñoz para 1961 y 1966-1967, que, además, permitirían comprobar la influencia de un nuevo ciclo de crecimiento económico. La comparación con las redes existentes a partir de 1975 nos permitirá comprobar tanto la vigencia de nuestro hipotético cártel bancario como su disolución progresiva, si esto último hubiera acontecido.

Dado que la hipótesis a contrastar sostiene que los protagonistas de la presunta colusión fueron los grandes bancos, las agrupaciones detectadas se han clasificado de acuerdo con el banco de mayor tamaño al que estuvieran asociadas. Con esta clasificación no se prejuzga que esto fuera efectivamente así. Se trata tan sólo de una forma de ordenar la información que, en todo caso, se adecua a la hipótesis a contrastar. Se han considerado como grandes bancos los siguientes: Hispano Americano, Español de Crédito (Banesto), Bilbao, Vizcaya y Central para todo el lapso estudiado; el Banco de Santander ascendió a la categoría de gran banco en los años cincuenta (aquí, a partir de las agrupaciones de 1961) y el Popular, en los sesenta (a partir de las agrupaciones de 1966-1967). También se presentan las vinculaciones entre bancos catalanes antes de la Guerra Civil, porque parecen jugar un papel importante a la hora de relacionar a los grandes bancos españoles entre sí. En el Apéndice 1 se presentan los listados de entidades de cada agrupación. Se han distinguido, por un lado, los bancos que mantenían más de un consejero común entre sí y, por otro, aquellos que estuvieran vinculados por un único consejero. Los primeros vienen a continuación del encabezamiento de cada año y los segundos se indican aparte en letra cursiva.

Es importante tener presente el criterio que se ha utilizado para delimitar las agrupaciones. Únicamente se han tenido en cuenta los consejeros comunes, al margen de cuáles hubieran podido ser las relaciones interbancarias en términos de propiedad de las acciones o de acuerdos explícitos para actuar conjuntamente, informaciones éstas poco conocidas hasta el momento, pero que serían las relevantes a la hora de delimitar los grupos bancarios reales. Sin embargo, en este trabajo no se pretende llevar a cabo esa tarea. Tan sólo se aspira a contrastar una de las hipótesis más aceptadas acerca del poder de la banca en España: la función coordinadora de los consejeros comunes. Por ello, las agrupaciones de bancos se han delimitado atendiendo únicamente a este criterio. La delimitación de los grupos reales exigiría un estudio más detenido de cada caso, que permitiera establecer las relaciones de propiedad, directas o a través de entidades interpuestas, así como los acuerdos estratégicos entre bancos para actuar de forma conjunta. Ciertamente, las conexiones 
mediante consejeros comunes proporcionan un primer esbozo de estas relaciones, pero sólo el estudio de cada caso concreto permitiría darles sentido y caracterizarlas, ya como significativas, ya como irrelevantes ${ }^{23}$.

La hipótesis a contrastar es la continuidad de las redes de consejeros comunes entre principios de la década de los veinte y finales de la de los sesenta. Su permanencia indicaría una gran fortaleza de los grupos bancarios y de las relaciones entre los mismos, lo que favorecería la hipótesis de la colusión. Alternativamente, su inestabilidad constituiría un indicio en contra de la inmutabilidad de las relaciones entre los grandes bancos y, especialmente, en contra de la existencia de colusión permanente. En tal caso, deberían considerarse otras explicaciones alternativas de la existencia de las redes detectadas en este trabajo. Este aspecto se trata en el quinto apartado, aunque no con la profundidad precisa, dada la escasez de investigaciones acerca de las estrategias de las empresas bancarias, sus métodos de expansión, organización interna y, en general, todo lo que constituye la historia de los bancos españoles. Tan sólo se apuntan algunas explicaciones posibles: asociaciones entre bancos en busca de complementariedades geográficas o especializaciones por tipo de negocio, maniobras previas a la absorción, relaciones sociales entre los dirigentes de las entidades, la propiedad de paquetes de acciones significativos o el ejercicio del voto por delegación (proxy-voting), sólo por citar algunas de las propuestas en la literatura especializada.

\section{Las redes de consejeros comunes en la banca española del siglo XX}

En este apartado examinaremos cronológicamente los resultados obtenidos. En el Apéndice 1 se presentan los miembros de cada agrupación y en el Apéndice 2 los organigramas con las relaciones entre estas agrupaciones, indicándose cuando ha parecido oportuno el banco que servía de puente. En el primer año de nuestra base de datos, 1915, apenas puede hablarse ni siquiera de la existencia de agrupaciones de bancos. Las únicas detectadas serían la pareja formada por los bancos de Bilbao y de Comercio y el trío reunido por el Hispano Americano. A éstas se añadirían algunas relaciones entre bancos catalanes, aunque los vínculos entre ellos son débiles porque consisten en un único consejero para cada par de entidades. En modo alguno puede hablarse de una red que conectara al conjunto de la banca española.

23 A estos efectos, las personas interesadas pueden consultar toda la información que ha servido para elaborar este trabajo en Pueyo (2006). 
La situación se complica en la década de los veinte, al aumentar los vínculos entre entidades. Los grandes bancos (excepto el Vizcaya) reúnen varias entidades a su alrededor mediante más de un consejero común y, lo que es más importante, se establecen vinculaciones entre las agrupaciones de los grandes bancos. Ésta es la red detectada en su día por Roldán y García Delgado. Sin embargo, debe dejarse constancia de dos grandes excepciones: los bancos Hispano Americano y Vizcaya se mantuvieron al margen. El primer caso es especialmente significativo porque, desde 1909, ocupaba la segunda posición del ranking según depósitos, detrás del Banco de España, al que superó en 1929. La red en cuestión se empieza a detectar en 1921, cuando encontramos vinculados de un modo u otro - a veces sólo mediante un único consejero y, en otras, a través de un banco pequeño que sirve de puente - cinco de las entidades que ocupaban los primeros puestos del ranking de depósitos: Banesto $\left(3^{\mathrm{a}}\right)$, Urquijo $\left(4^{\mathrm{a}}\right)$, Bilbao $\left(5^{\mathrm{a}}\right)$, Central $\left(6^{\mathrm{a}}\right)$ y Crédito de la Unión Minera ( $\left.8^{\mathrm{a}}\right)$. En 1925 se mantiene la densidad de relaciones, pero se van delimitando más claramente dos agrupaciones, centradas alrededor del Urquijo y de Banesto. También se observa cómo se ha complicado la malla tejida entre los bancos catalanes, que parecen agruparse alrededor de tres o cuatro entidades: la Banca Arnús, la S. A. Arnús Garí o la Banca Marsans y, finalmente, el Banco de Cataluña. Al mismo tiempo, el Sindicato de Banqueros, el Banco Internacional de la Industria y el Comercio, y el Hispano Colonial servían de puente entre todas las entidades citadas.

Aparentemente, el estado de las relaciones interbancarias en la década de los veinte revestiría una enorme complejidad, con relaciones cruzadas entre buena parte de los bancos grandes y medianos ${ }^{24}$. Sin embargo, si aclaramos el dibujo reuniendo a los bancos más firmemente vinculados bajo la etiqueta del banco de mayor tamaño al que estuvieran asociados (véanse los organigramas del Apéndice 2), el aspecto de red desaparece en gran parte y, en realidad, tan sólo subsiste para los bancos catalanes. Los grandes bancos madrileños y bilbaínos aparecen vinculados débilmente mediante un único consejero y, en ocasiones, a través de un banco de menor tamaño que se interpone entre ambos. Es decir, la red general de bancos es más un fenómeno específicamente catalán que español.

En 1934 nos encontramos con que han desaparecido buena parte de las vinculaciones de la década anterior y la red se limita a relacionar las agrupaciones del Urquijo y el Central a través de dos bancos catalanes. Las otras agrupaciones aparecen claramente separadas unas de otras, la de Banesto ha desaparecido por absorción y sólo los bancos catalanes siguen manteniendo la malla de relaciones, con la novedad de la aparición en ella del Banco Central. 
De acuerdo con la tesis de la monopolización de la banca, el incremento del número de vínculos durante la I Guerra Mundial y la década de los veinte se explicaría como el resultado del proceso de oligopolización, iniciado en los años de la Gran Guerra y favorecido por la Ley de Ordenación Bancaria de 1921. Sin embargo, en coherencia con esta interpretación, deberíamos deducir que el intento de monopolización fracasó entre 1925 y 1934, a la vista de la desaparición de muchas de las relaciones anteriores, o que, al menos, hubo un cambio radical en la estrategia practicada hasta ese momento. Cambio, sin embargo, que no ha sido planteado hasta ahora por los defensores de dicha hipótesis.

Los años inmediatamente posteriores a la Guerra Civil resultan bastante confusos, primero, por la reunificación monetaria y, segundo, por la liquidación de las operaciones bancarias llevadas a cabo durante el conflicto. A partir de 1942 se reanudan las operaciones bancarias con cierta normalidad y, en 1946, el Régimen aprovecha la renovación del monopolio de emisión del Banco de España para reformar la Ley de Ordenación Bancaria y consolidar el statu quo implantado durante la Guerra Civil y la inmediata posguerra. Este es el contexto en el que se desarrollaron las agrupaciones detectadas para 1946. Aunque se aprecia que los grandes bancos mantenían un número relativamente cuantioso de consejeros comunes con otras entidades, no existe ninguna red que vincule al conjunto de la gran banca. Tan sólo Banesto y el Banco de Bilbao aparecen relacionados, pero a través de dos entidades intermedias. En plena autarquía, que ha sido considerada la edad dorada del monopolio bancario, nos encontramos con unos grupos bien perfilados en torno a cada una de las grandes entidades. Al margen de cuáles fueran las intenciones de cada una de éstas para reunir una serie de bancos a su alrededor, no existe ninguna red que relacione todo el conjunto, como predeciría la tesis de la monopolización. No parece que la regulación del statu quo ni las facilidades que, según la literatura especializa$\mathrm{da}$, encontraron los bancos durante los años cuarenta, propiciaran el establecimiento de relaciones entre los miembros de la gran banca, al menos mediante consejeros comunes.

En la década de los sesenta se registra un fenómeno similar al del período de entreguerras. En 1961, los vínculos entre las agrupaciones de los grandes bancos han aumentado respecto de 1946 y, aún más, en 1966-1967, cuando sí se aprecia una red tupida. Sin embargo, este entramado ha desaparecido de nuevo en 1975. Igual que en el lapso anterior a la Guerra Civil, si los grandes bancos españoles intentaron utilizar una red de consejeros comunes para sostener unos hipotéticos pactos colusivos, en algún momento a partir de 1967 hubo un cambio de estrategia o, quizá, la colusión fracasó.

La coincidencia entre crecimiento económico intenso y formación de redes de consejeros comunes que se registra en las décadas de los veinte y de los sesenta permite plantear la hipótesis alternativa de que los bancos buscaran ampliar su esfera 
de negocios aprovechando el ciclo de crecimiento, mediante el establecimiento de relaciones con otras entidades, que incluirían el intercambio de consejeros. Los consejeros comunes constituirían un reflejo de las estrategias de crecimiento practicadas por las entidades financieras en unas coyunturas de fuerte expansión del conjunto de la economía. Las recesiones económicas y las crisis políticas posteriores habrían aconsejado un cambio de estrategia y, en consecuencia, habrían desaparecido los vínculos y los consejeros comunes.

En 1980 vuelve a aparecer una red de consejeros comunes, aunque como puede observarse en el organigrama correspondiente, los grandes bancos se sitúan en los márgenes de la misma. Observada con más detalle, vemos que las entidades que los vinculan son dos sociedades con participación de capitales foráneos y dos grupos de bancos intervenidos en aquel momento por las autoridades financieras. Como se sabe, la crisis bancaria de 1977-1985 se resolvió gracias a la colaboración entre el sector público (Banco de España, Fondo de Garantía de Depósitos y Corporación Bancaria) y el sector privado. De esta manera, no fue necesario liquidar un gran número de bancos, ya que la mayoría fueron saneados por las instituciones públicas creadas para enfrentar el problema y, posteriormente, vendidos a los bancos privados para que procedieran a resituarlos en el mercado. Las relaciones que se detectan en la década de los ochenta tendrían su origen en este tipo de operaciones de saneamiento ${ }^{25}$.

Una vez resuelta la crisis bancaria, y con la economía española integrada en la Comunidad Europea, nos encontramos con una serie de adquisiciones y cambios de razón social que acaban desembocando en los grupos bancarios de la actualidad. Estos grupos se encuentran formados por un banco grande, con vocación de banca universal, que se acompaña de entidades especializadas en segmentos particulares (banca privada, e-banca, etc.). No se han encontrado consejeros comunes que relacionen a la gran banca en la fecha final de 1990, salvo la vinculación entre Banesto y el BBV a través del Banco Saudí Español.

\section{Relaciones interempresariales en la banca española del siglo XX}

A la vista de la evidencia empírica reunida, ha de descartarse que los consejeros comunes hayan sido utilizados para mantener un acuerdo colusivo permanente entre los grandes bancos españoles. Si en algún momento su existencia refleja una hipotética cartelización del sector, ésta se limitó a dos períodos, las décadas de los 
veinte y de los sesenta, únicos momentos en que encontramos una trama de vínculos entre buena parte de los grandes bancos, aunque no los incluyera a todos. Fuera de estas dos etapas, los grandes bancos se mantuvieron separados unos de otros o vinculados indirectamente a través de una o varias entidades interpuestas. Lo que sí ha quedado al descubierto es un fenómeno de formación y disolución de agrupaciones y redes bancarias, cuyo análisis podría servir de base para la investigación de las estrategias empresariales de la gran banca y la formación de los mercados financieros contemporáneos. Si bien este trabajo requiere investigaciones de mayor calado, una revisión somera de la evidencia reunida con ayuda de fuentes secundarias permite plantear inmediatamente algunas explicaciones alternativas de la existencia de las agrupaciones y redes bancarias detectadas.

La historia del Banco Hispano Americano proporciona algunos ejemplos de relaciones interbancarias, con consejeros comunes incluidos, pero sin pretensiones colusivas aparentes $^{26}$. El banco fue fundado en 1900 por un grupo de hombres de negocios procedentes del mismo ambiente: el comercio y las finanzas americanas. Entre ellos se encontraba Florencio Rodríguez, que era por entonces el principal accionista del Banco de Gijón. Esta conexión se tradujo en la presencia de consejeros comunes en los consejos del Hispano y el Gijón. La relación con el Herrero tendría un origen similar. El Banco Herrero fue fundado en 1911 con la participación de Florencio Rodríguez, quien negoció la toma de acciones de la nueva entidad por parte del Hispano y sus consejeros. La dirección del Hispano vio la operación con buenos ojos y consideró la posibilidad de que el nuevo banco actuara como su agente en Asturias. De esta manera, aparece una segunda hipótesis explicativa de las relaciones interbancarias. En un momento en que los bancos no mantenían redes de sucursales, el establecimiento de acuerdos con entidades de otras zonas era una forma de ampliar la esfera de negocios y facilitar el movimiento de fondos. Se sabe que el Hispano Americano llegó a un acuerdo con los bancos Herrero y de Gijón, según el cual sus operaciones en Asturias se realizarían a través de estas entidades ${ }^{27}$. En 1920, se firmó un acuerdo similar entre el Hispano y el Banco de San Sebastián, que supuso también la compra por el primero del 50 por 100 de las acciones del segundo ${ }^{28}$.

En el caso del Hispano Americano, debe destacarse la escasez de relaciones con otros grandes bancos durante el siglo XX. De hecho, parece que esta entidad evitó, en la medida de lo posible, abusar de la presencia de consejeros comunes con otras entidades bancarias o empresas no financieras. Véase Tortella y García Ruiz (1999), p. 68.

$27 \quad$ Véase García Ruiz (2003), p. 22. El acuerdo en cuestión seguía vigente en 1965.

28 Véanse las circunstancias de la fundación del Banco Hispano Americano en García Ruiz (1999); sobre los bancos de Gijón y Herrero, Anes (1999); y las relaciones con el Banco de San Sebastián, en Muñoz (1978), p. 147, y Cabana (1972), p. 231. 
El Hispano Americano también protagonizó otro ejemplo de complementariedad, esta vez funcional, que incluyó el intercambio de consejeros. Después de la Guerra Civil, el Hispano Americano se asoció con el Urquijo, lo que supuso reunir los grupos bancarios de ambas entidades. En 1944 se firmó el llamado "Pacto de las Jarillas", que oficializó las relaciones entre ambos. El acuerdo supuso el intercambio de acciones y consejeros, y la absorción por el Hispano de todas las filiales del Urquijo. A cambio, el segundo obtuvo una línea de crédito para financiar sus promociones industriales. El objetivo explícito consistía en sumar las ventajas de la especialización del Hispano Americano en banca comercial con la vocación industrial del Urquijo y combinarlas mediante la cooperación de las dos entidades $^{29}$.

El Banco Urquijo aparece como un ejemplo complejo de relaciones con otras entidades, con consejeros comunes de por medio. El Urquijo formó varias filiales, cada una con personalidad jurídica diferenciada, dando entrada en las mismas a personalidades relevantes del mundo económico local, que en algunos casos eran consejeros de bancos de la zona. Las motivaciones mezclarían consideraciones sociales, estrategias de acceso a otros mercados geográficos y búsqueda de socios con los que compartir negocios ${ }^{30}$. Otro caso complejo de relaciones interbancarias lo encontramos en la fundación del Banco Central, que fue aprovechada por una serie de bancos locales y regionales para asociarse con un corresponsal de peso en Madrid, sin que exista constancia de que se intentara ningún otro tipo de coordinación ${ }^{31}$. En el primer tercio del siglo XX, cuando se estaba formando el mercado bancario español, esta vía resultaría especialmente provechosa para bancos que mantuvieran oficinas abiertas en zonas geográficas separadas.

Otras conexiones podrían tener un origen casual, no buscadas intencionadamente. Así, la relación establecida entre el Banco Central y el Hispano Colonial en 1934 es el ejemplo más conocido de reparto geográfico entre bancos asociados. Sin embargo, es difícil ver en la narración de los hechos que desembocaron en este acuerdo algo más que la mera búsqueda de oportunidades de negocio a corto plazo, que acabó convirtiéndose, inesperadamente, en la vía de salvamento del Central

\footnotetext{
29 Poco se sabe del contenido de este pacto. Véanse algunos detalles en las reseñas biográficas de Juan Lladó y Andrés Moreno incluidas en Torres (2000), así como Tortella y García Ruiz (1999), pp. 206-213.

Véase Díaz Hernández (1998), p. 164 y ss.

Arroyo (2003, pp. 35 y ss.) considera que el episodio de la fundación del Banco Central debería contemplarse como la culminación de un modelo de coordinación bancaria mediante la formación de federaciones de entidades, de las que proporciona varios ejemplos para los años anteriores a la I Guerra Mundial. El contenido del acuerdo consistiría en la toma de participaciones en el capital, el respeto de los mercados geográficos de cada socio y el establecimiento de relaciones de corresponsalía en régimen de exclusividad. Arroyo señala que estas federaciones acabaron en muchas ocasiones en tomas de control y absorciones.
} 
después de la Guerra Civil ${ }^{32}$. Siguiendo con el caso del Banco Central, tras el conflicto bélico protagonizó otro caso de colaboración entre bancos, que dejó algunos rastros en forma de consejeros comunes. El Central intentó organizar una asociación de bancos (Bancor) que se complementasen geográficamente y mantuvieran una colaboración permanente y solidaria. Esta asociación incluía al Banco de Valencia y a dos bancos participados por el Central, el Hispano Colonial y el Banco de Crédito de Zaragoza. En 1946 se asociaron los bancos Popular y Santander, aunque no se conoce el grado de coordinación que pudiese haber entre estos dos últimos y el resto de Bancor. En palabras de Francesc Cabana, al menos los bancos Popular y Santander "salvaguardaban su autonomía" y, en el caso del Santander, además, nos dice que la relación con el Central se fundamentaba en la participación conjunta en diversas empresas, entre ellas el Hispano Colonial ${ }^{33}$. Finalmente, entre 1947 y 1951, el Central procedió a absorber a los bancos con los que estaba más relacionado y la agrupación Bancor se deshizo en 1951, para no dar pie a "mengua de autonomía" de los bancos Popular y de Valencia, aunque la razón más probable sería el deseo del Banco Popular de actuar por su cuenta. ${ }^{34}$ El ejemplo de Bancor mostraría las dificultades que encontraron los bancos españoles para mantener la colaboración entre entidades que, a fin de cuentas, actuaban en los mismos mercados y que, en el fondo, eran rivales.

\section{Conclusiones}

Varios autores han defendido la hipótesis de que la banca española ha actuado durante el siglo XX como si se tratara de un monopolio, cuyos protagonistas habrían sido los grandes bancos, pero "la situación real de la banca sólo se puede analizar debidamente si tenemos en cuenta los grupos bancarios que encabezan los grandes establecimientos" ${ }^{\prime \prime 3}$. Diversos investigadores procedieron a delimitar los grupos bancarios indirectamente, mediante unos tipos de conexiones que consideraron plenamente significativas: los consejeros comunes y sus vinculaciones familiares, las relaciones institucionalizadas a través del Consejo Superior Bancario, las derivadas del

32 El motivo inicial del Banco Central para comprar acciones del Hispano Colonial a partir de 1932 fue meramente especulativo. La cotización del Hispano Colonial iba a la baja, pero se confiaba en sacar buenos rendimientos ante la perspectiva de una fusión del Hispano Colonial con la Banca Marsans y el Crédito y Docks (Tortella, 2002, p. 267, y Cabana, 1972, pp. 37-43).

Cabana (1965), p. 242.

Cabana (1965), p. 242; y (1972), pp. 45-49 y 239-245.

Muñoz (1969), p. 103. 
control de la banca oficial y las que existiesen a través de empresas no financieras. Sus conclusiones fueron siempre coincidentes. Se demostraba la existencia de una red muy densa de relaciones entre todos los grandes bancos a través de la participación de unas mismas personas en varios consejos de administración simultáneamente. De esta manera, aseguraban, la gran banca coordinaba sus actuaciones con un objetivo común: la maximización de los beneficios conjuntos por la vía de la monopolización de los mercados financieros. Además, se defendía que esta red se había mantenido de forma estable, como mínimo, desde los años de la I Guerra Mundial hasta más allá del final del franquismo.

En este trabajo se ha repetido ese tipo de análisis de una forma más sistemática. Se han establecido los grupos bancarios de acuerdo con el mismo método para una serie de años que cubren todo el siglo XX, con objeto de comprobar si la red propugnada por los defensores de la hipótesis del monopolio bancario existió durante toda la centuria o fue un fenómeno propio de una época o unas circunstancias concretas. A tenor de los resultados de nuestra investigación, la historia de las relaciones interbancarias parece más complicada de lo previsto en la hipótesis tradicional. La composición de los grupos reunidos por los grandes bancos varió en el tiempo y no existieron vínculos permanentes entre los mismos. En consecuencia, debe descartarse que los consejeros comunes constituyeran un mecanismo de coordinación de un hipotético cártel bancario que se hubiera mantenido durante varias décadas. Las redes de consejeros resultan especialmente densas en dos de las fechas analizadas, 1925 y 1966-1967. Ambas destacan por encontrarse dentro de las dos décadas en que la economía española ha crecido con mayor intensidad en el siglo XX. Sin embargo, las tramas detectadas en estos años se deshicieron, de tal manera que poco más tarde nos encontramos con que cada gran banco mantiene una agrupación claramente separada de las demás.

Hasta después de la I Guerra Mundial cada uno de los futuros grandes bancos mantuvo unas relaciones muy limitadas con otras entidades. Es en 1921-1925 cuando se observa la formación de una red que llega a englobar a un gran número de unidades. Sin embargo, este fenómeno no puede achacarse sin más a una búsqueda de coordinación oligopolista, de la que, además, se habrían mantenido al margen dos de las mayores entidades, el Hispano Americano y el Vizcaya. Otras opciones son posibles como, por ejemplo, la búsqueda de socios para acceder a mercados geográficos lejanos, para participar en operaciones sindicadas o como candidatos a futuras absorciones. Tampoco deben descartarse otras motivaciones, como el mantenimiento de una agenda de relaciones sociales o, simplemente, la compra de paquetes de acciones como mera inversión financiera. En todo caso, si la red fuera una prueba de colusión, entonces ésta habría fracasado entre 1925 y 1934 o la estrategia de coordinación habría sufrido un vuelco fundamental. En cambio, si no fuera más que un indicio de las tácticas de crecimiento de las entidades, el enrarecimiento del clima 
económico y político bastaría para explicar que los bancos esperaran mejores tiempos para continuar el proceso de expansión.

Tras la imposición del statu quo, no se aprecia que la hipotética colusión bancaria se instrumentalizara a través del mantenimiento de consejeros comunes. Hasta 1961, cada grupo se mantiene separado del resto. Sólo en los años sesenta nos encontramos con la formación, de nuevo, de una red que relacionaba a buena parte de la banca española. Pero, de la misma manera que antes de la Guerra Civil, una década más tarde la trama se había deshecho. La historia parece haberse repetido, aunque ahora queda más claro que la promulgación de una nueva Ley de Ordenación Bancaria, en 1946, no afectó, al menos de modo inmediato, a la formación del tipo de vinculaciones que estamos estudiando.

Finalmente, las relaciones que se detectan entre 1980 y 1990 no serían más que un subproducto de la coyuntura: la crisis bancaria, que dio como resultado que los grandes bancos se hicieran con el control de las entidades en crisis. Otra serie de relaciones, cada vez más numerosas a medida que nos acercamos al final del siglo XX, estarían motivadas por la formación de holdings financieros dirigidos por los grandes bancos, cada uno de los cuales reuniría a su alrededor a otras entidades especializados en ciertos segmentos del negocio financiero. No se trata, pues, de ningún tipo de coordinación oligopolista, sino de bancos universales que han encomendado a una unidad jurídica separada una porción de su actividad.

\section{Bibliografía}

AA. VV. (1954): Notas sobre política económica española, Madrid, Publicaciones de la Delegación Nacional de FET y de las JONS.

ANES, Rafael (1999): "Sociedades mercantiles y banca en Asturias a comienzos del siglo XX", en TEDDE, Pedro (ed.), Economía y colonias en la España del 98, Madrid, Síntesis-Fundación Duques de Soria, pp. 322-336.

ARROYO, Víctor (2003): “La banca en España en el período de entreguerras, 19201935. Un modelo de modernización y crecimiento", en Informaciones: Cuadernos de Archivo, V, 72-75, Bilbao, BBVA Archivo Histórico.

CABANA, Francesc (1965): La banca a Catalunya, Barcelona, Edicions 62.

-(1972): Bancs i banquers a Catalunya, Barcelona, Edicions 62.

CAPIE, Forrest, y BILLINGS, Mark (2004): “Evidence on competition in English commercial banking, 1920-70", Financial History Review, 11, 1, pp. 69-103.

COLLINS, Michael (1988): Money and Banking in the UK. A History, London, Routledge. CUERVO, Álvaro (1988): La crisis bancaria en España, 1977-1985. Causas, sistemas de tratamiento y coste, Barcelona, Ariel. 
DE LA SIERRA, Fermín (1951): “La situación monopolística de la banca privada en España”, Revista de Economía Política, 3, 1-2, pp. 1-51.

DELL'ARICCIA, Giovanni (2001): “Asymmetric information and the structure of the banking industry", European Economic Review, 45, pp. 1.957-1.980.

DÍAZ HERNÁNDEZ, Onésimo (1998): Los Marqueses de Urquijo. El apogeo de una saga poderosa y los inicios del Banco Urquijo, 1870-1931, Pamplona, Ediciones de la Universidad de Navarra.

FANJUL, Óscar, y MARAVALL, Fernando (1982): "Estructura de mercado y crecimiento del sistema bancario español: un análisis de las tres últimas décadas", Cuadernos Económicos de ICE, 21, pp. 101-118.

-(1985): La eficiencia del sistema bancario español, Madrid, Alianza.

FAUS, Esteban Ma (2001): Regulación y desregulación. Notas para la historia de la banca española, Barcelona, Península.

FOHLIN, Caroline (1999): "The Rise of Interlocking Directorates in Imperial Germany", Economic History Review, 52, 2, pp. 307-333.

GARCÍA DELGADO, José Luis, y JIMÉNEZ, Juan Carlos (1999): Un siglo de España. La economía, Madrid, Marcial Pons.

GARCÍA RUIZ, José Luis (1999): “La nueva banca mixta en Madrid de comienzos de siglo", en TEDDE, Pedro, (ed.), Economía y colonias en la España del 98, Madrid, Síntesis-Fundación Duques de Soria, pp. 261-297.

-(2002): "Los arreglos interbancarios durante el franquismo", Revista de Historia Económica, XX, 2, pp. 365-386.

-(2003): "Los flujos financieros regionales en la España del siglo XX: una perspectiva desde la historia bancaria", Revista de Estudios Regionales, 67, pp. 15-54.

GARCÍA RUIZ, José Luis, y TORTELLA, Gabriel (2003): “Banca y política durante el primer franquismo", en SÁNCHEZ RECIO, Glicerio, y TASCÓN, Julio, (eds.), Los empresarios de Franco. Política y economía en España, 1936-1957, Barcelona, Crítica, pp. 67-100.

GUINNANE, Timothy W. (2002): “Delegated monitors, large and small: Germany's banking system, 1800-1914", Journal of Economic Literature, 40, 1, pp. 73-124.

HERMALIN, Benjamin, y WEISBACH, Michael (2003): "Boards of directors as an endogenously determined institution: A survey of the economic literature", Federal Reserve Bank of New York Economic Policy Review, april, pp. 7-26.

HILFERDING, Rudolf (1985 [1910]): El capital financiero, Madrid, Tecnos.

MACE, Myles (1986): Directors: Myth and Reality, Boston, Harvard Business School Press.

MUÑOZ, Juan (1969): El poder de la banca en España, Madrid, ZYX.

-(1978): "La expansión bancaria entre 1919 y 1926: la formación de una banca nacional", Cuadernos Económicos de ICE, 6, pp. 98-162. 
MUÑOZ LINARES, Carlos (1952): “La concentración de capital en las sociedades y empresas españolas", Revista de Economía Política, 4, 1, pp. 221-259.

-(1955): "El pliopolio en algunos sectores del sistema económico español", Revista de Economía Política, 7, 1, pp. 3-66.

PONS, M ${ }^{a}$ Ángeles (1999): “Capture or agreement? Why Spanish banking was regulated under the Franco regime (1939-1975)", Financial History Review, 6, 1, pp. 2546.

-(2001): "Oligopolio y tipos de interés en la banca española, 1942-1975", Revista de Historia Económica, XIX, 3, pp. 679-703.

-(2002): Regulating Spanish banking, 1939-1975, Ashgate, Aldershot.

POVEDA, Raimundo (1980): "Política monetaria y financiera", en GÁMIR, Luis, (ed.), Política económica de España, vol. 1, Madrid, Alianza, pp. 71-132.

PUEYO, Javier (2003): "Oligopolio y competencia en la banca española del siglo XX", Revista de Historia Económica, XXI, 1, pp. 147-194.

-(2006): "Interlocking directorates in Spanish banking in the twentieth century", Departament d'Economia i Empresa, Universitat Pompeu Fabra, Working Paper Ref. 391.

-(en prensa): El comportamiento de la gran banca en España, 1921-1974, Madrid, Banco de España, Servicio de Estudios, Estudios de Historia Económica.

ROLDÁN, Santiago, y GARCÍA DELGADO, José Luis (1973): La formación de la sociedad capitalista en España, 1914-1920, Madrid, CECA.

SHAFFER, Sherrill (2004): "Patterns of competition in banking", Journal of Economics and Business, 56, pp. 287-313.

TAMAMES, Ramón (1961): La lucha contra los monopolios, Madrid, Tecnos.

-(1977): La oligarquía financiera en España, Barcelona, Planeta.

TERMES, Rafael (1991): Desde la banca, 2 vol., Madrid, Rialp.

TOMKA, Béla (2001): "Interlocking Directorates between banks and Industrial Companies in Hungary at the Beginning of the Twentieth Century", Business History, 43,1 , pp. 25-42.

TORRES, Eugenio (ed.) (2000): Los 100 empresarios españoles del siglo XX, Madrid, LID. TORTELLA, Gabriel (1995): El desarrollo de la España contemporánea, Madrid, Alianza. -(2002): "El Banco Central en el período de entreguerras o cómo llevar una empresa a la ruina", Estudis d'Història Econòmica, 17-18, pp. 241-272.

TORTELLA, Gabriel, y GARCÍA RUIZ, José Luis (1999): Una historia de los bancos Central e Hispano Americano. Un siglo de gran banca en España, trabajo inédito. 
APÉNDICE 1

LISTADOS DE AGRUPACIONES BANCARIAS ${ }^{36}$

\subsection{Relaciones del Banco Hispano Americano}

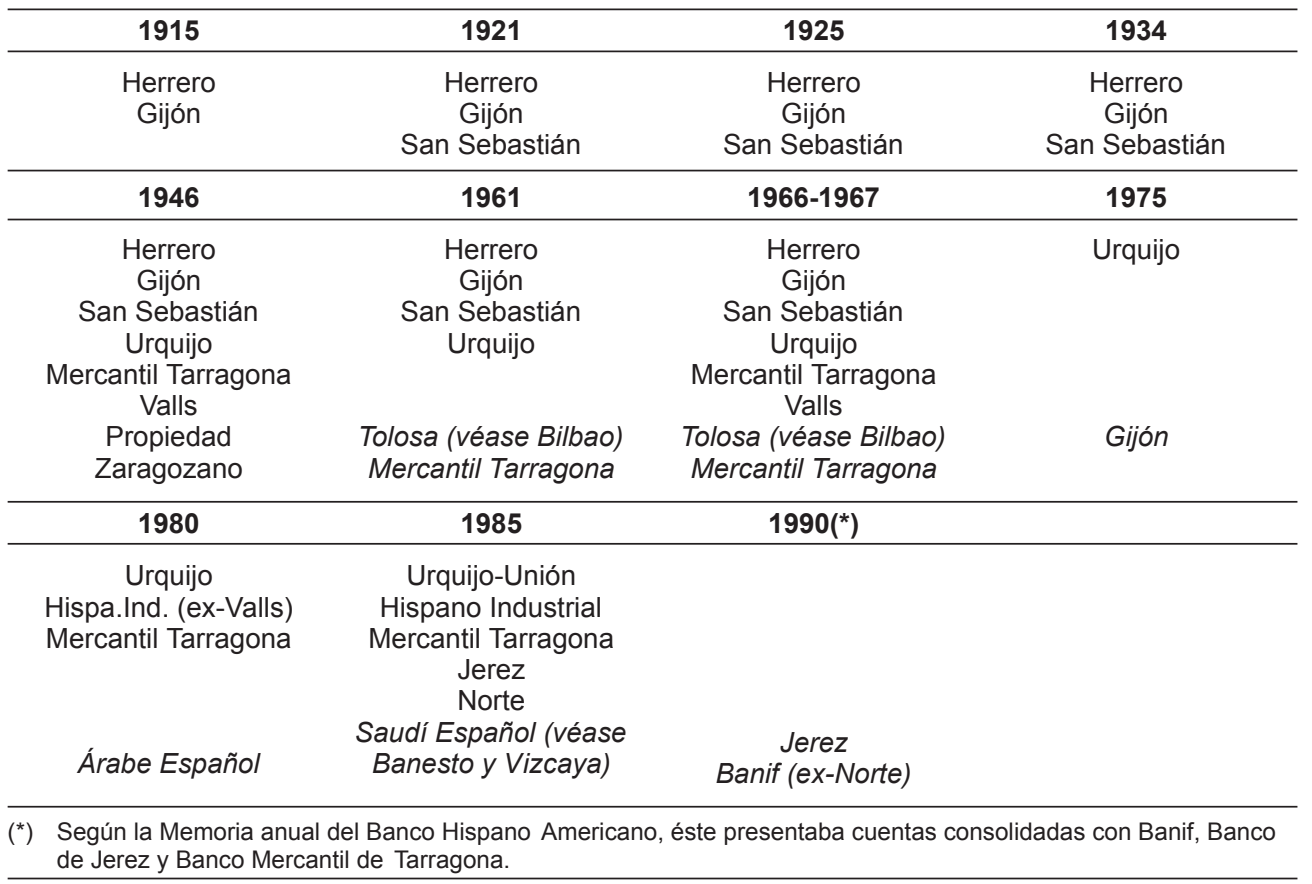

\subsection{Relaciones del Banco Urquijo $\left({ }^{*}\right)$}

\begin{tabular}{cccc}
\hline 1915 & 1921 & 1925 & 1934 \\
\hline Urquijo Catalán & Urquijo Catalán & Urquijo Catalán \\
Urquijo Vascongado & Urquijo Vascongado & Urquijo Vascongado \\
Urquijo Guipúzcoa & Urquijo Guipúzcoa & Urquijo Guipúzcoa \\
Minero Ind. Asturias & Minero Ind. Asturias & Minero Ind. Asturias \\
Valencia & Oeste de España \\
& Asturiano & Asturiano & Mercantil Tarragona \\
& Banesto & Banesto-Gijonés de & Valls \\
Gijonés de Créd. & Créd.-Com. Español & Hispano Colonial \\
Hispano Colonial & Hispano Colonial & (véase Central) \\
& Burgos & Arnús \\
& Bilbao & Créd. y Docks \\
& & &
\end{tabular}

(*) A partir de 1944, el Banco Urquijo pasa a formar parte de las relaciones del Banco Hispano Americano.

36 En cursiva se indican los bancos relacionados mediante un único consejero con alguna de las entidades de la agrupación. 


\subsection{Relaciones del Banco Español de Crédito}

\begin{tabular}{|c|c|c|c|}
\hline 1915 & 1921 & 1925 & 1934 \\
\hline \multirow[t]{2}{*}{ Hipotecario } & $\begin{array}{c}\text { Gijonés de Créd. } \\
\text { Com. Español }\end{array}$ & $\begin{array}{c}\text { Gijonés de Créd. } \\
\text { Com. Español } \\
\text { Oviedo }\end{array}$ & \\
\hline & $\begin{array}{c}\text { Urq. Guipuzcoano } \\
\text { Castellano } \\
\text { (véase Central) } \\
\text { Oviedo }\end{array}$ & Urq. Guipuzcoano & \\
\hline 1946 & 1961 & $1966-1967$ & 1975 \\
\hline $\begin{array}{c}\text { Guipuzcoano } \\
\text { Vitoria }\end{array}$ & $\begin{array}{c}\text { Guipuzcoano } \\
\text { Vitoria } \\
\text { Epifanio Ridruejo }\end{array}$ & $\begin{array}{l}\text { Guipuzcoano } \\
\text { Vitoria } \\
\text { Epifanio Ridruejo } \\
\text { Bandesco } \\
\text { Garriga Nogués }\end{array}$ & $\begin{array}{c}\text { Guipuzcoano } \\
\text { Bandesco }\end{array}$ \\
\hline $\begin{array}{c}\text { Pastor } \\
\text { Epifanio Ridruejo } \\
\text { Fom. Agric. Mallorca } \\
\text { (véase Bilbao) }\end{array}$ & Masaveu & $\begin{array}{c}\text { Masaveu } \\
\text { Sindicato Banqueros } \\
\text { (véase Central y } \\
\text { Santander) } \\
\text { Ind.Cataluña } \\
\text { (véase Popular) }\end{array}$ & Masaveu \\
\hline 1980 & 1985 & $1990\left(^{*}\right)$ & \\
\hline $\begin{array}{c}\text { Guipuzcoano } \\
\text { Bandesco }\end{array}$ & $\begin{array}{c}\text { Guipuzcoano } \\
\text { Bandesco } \\
\text { Garriga Nogués } \\
\text { Madrid } \\
\text { Catalán Desarrollo }\end{array}$ & $\begin{array}{c}\text { Bandesco } \\
\text { Madrid } \\
\text { Català Crèd. } \\
\text { (ex-Catalán Desarrollo) } \\
\text { General }\end{array}$ & \\
\hline Saudí Español & $\begin{array}{c}\text { Saudí Español } \\
\text { (véase Hispano } \\
\text { Americano } \\
\text { y Vizcaya) } \\
\text { Vitoria (véase } \\
\text { Santander) }\end{array}$ & $\begin{array}{c}\text { Vitoria } \\
\text { Saudí Español } \\
\text { (véase BBV) } \\
\text { Garriga Nogués } \\
\text { Peninsular } \\
\text { Alicantino } \\
\text { Albacete }\end{array}$ & \\
\hline
\end{tabular}

$\left(^{*}\right)$ Según la Memoria anual, Banesto era propietario de los siguientes bancos: Madrid (98 por 100), Català de Crédit (70 por 100), Vitoria (85 por 100), Desarrollo Económico Español (92 por 100) y General (100 por 100). 


\subsection{Relaciones del Banco Central}

\begin{tabular}{ccc}
\hline 1921 & 1925 & 1934 \\
\hline Créd. Unión Minera & $\begin{array}{c}\text { Castellano } \\
\text { Créd. Zaragoza }\end{array}$ & $\begin{array}{c}\text { Badalona } \\
\text { Hispano Colonial } \\
\text { Arnús } \\
\text { Créd. y Docks } \\
\text { Menorca }\end{array}$ \\
& & \\
Bilbao & Bilbao-Comercio & $\begin{array}{c}\text { Créd. Zaragoza } \\
\text { Carquijo Catalán } \\
\text { Propiedad }\end{array}$ \\
(véase Banesto) & & López Quesada \\
Santander & & \\
Cía. Créd. Bancario & &
\end{tabular}

\begin{tabular}{|c|c|c|c|}
\hline 1946 & 1961 & 1966-1967 & 1975 \\
\hline $\begin{array}{l}\text { Hispano Colonial } \\
\text { Créd. y Docks } \\
\text { Menorca } \\
\text { Valencia } \\
\text { Popular }\end{array}$ & $\begin{array}{l}\text { Créd. y Docks } \\
\text { Valencia } \\
\text { Agric. Aragonés } \\
\text { Popular } \\
\text { Andalucía } \\
\text { Salamanca }\end{array}$ & $\begin{array}{c}\text { Créd. y Docks } \\
\text { Valencia } \\
\text { Agric. Aragonés } \\
\text { Aragón (v. Hispano) } \\
\text { Úbeda } \\
\text { Fomento }\end{array}$ & $\begin{array}{l}\text { Valencia } \\
\text { Fomento }\end{array}$ \\
\hline $\begin{array}{c}\text { Santander } \\
\text { Jerez } \\
\text { Tusquets } \\
\text { Sindicato Banqueros } \\
\text { Badalona }\end{array}$ & $\begin{array}{c}\text { Sindicato Banqueros } \\
\text { (véase Santander) } \\
\text { La Coruña }\end{array}$ & $\begin{array}{c}\text { Andalucía } \\
\text { (véase Popular) } \\
\text { Sindicato Banqueros } \\
\text { (véase Banesto, } \\
\text { Santander) } \\
\text { Atlántico } \\
\text { Exterior } \\
\text { Urquijo } \\
\text { Créd. Navarro } \\
\text { Ind. Cataluña } \\
\text { (véase Banesto } \\
\text { y Popular) } \\
\text { Catalán Desarrollo }\end{array}$ & \\
\hline 1980 & 1985 & $1990\left(^{*}\right)$ & \\
\hline $\begin{array}{l}\text { Valencia } \\
\text { Fomento }\end{array}$ & $\begin{array}{c}\text { Fomento } \\
\text { Granada } \\
\text { Créd. e Inv. } \\
\text { Internal. Com. }\end{array}$ & $\begin{array}{c}\text { Valencia } \\
\text { Fomento } \\
\text { Granada } \\
\text { Gallego (ex-Créd. e Inv.) } \\
\text { Internal. Com. }\end{array}$ & \\
\hline Granada & $\begin{array}{c}\text { Valencia } \\
\text { Noroeste } \\
\text { Sevilla }\end{array}$ & Valencia & \\
\hline
\end{tabular}

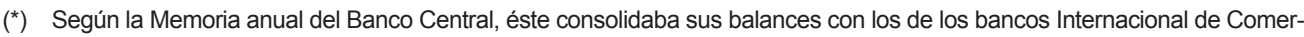
cio (99,9 por 100), Gallego (99,5 por 100), de Granada (99 por 100), de Fomento (52 por 100) y de Valencia (16 por 100). 
1.5. Relaciones del Banco de Bilbao $\left(^{*}\right)$

\begin{tabular}{|c|c|c|c|}
\hline 1915 & 1921 & 1925 & 1934 \\
\hline Comercio & Comercio & Comercio & $\begin{array}{l}\text { Comercio } \\
\text { Asturiano }\end{array}$ \\
\hline Cartagena & $\begin{array}{c}\text { Central } \\
\text { Sindicato Banqueros }\end{array}$ & $\begin{array}{c}\text { Asturiano } \\
\text { (véase Urquijo) } \\
\text { Internal. Ind. y Com. } \\
\text { Central }\end{array}$ & Castellano \\
\hline 1946 & 1961 & $1966-1967$ & 1975 \\
\hline $\begin{array}{c}\text { Comercio } \\
\text { Asturiano } \\
\text { Fom.Agric.Mallorca } \\
\text { (véase Banesto) }\end{array}$ & $\begin{array}{l}\text { Comercio } \\
\text { Asturiano } \\
\text { Castellano }\end{array}$ & $\begin{array}{c}\text { Comercio } \\
\text { Ind. de Bilbao } \\
\text { Asturiano } \\
\text { Castellano }\end{array}$ & $\begin{array}{c}\text { Comercio } \\
\text { Ind. de Bilbao }\end{array}$ \\
\hline $\begin{array}{l}\text { Castellano } \\
\text { La Coruña } \\
\text { Tolosa }\end{array}$ & $\begin{array}{c}\text { La Coruña } \\
\text { (véase Central) } \\
\text { Tolosa (véase Hispano) }\end{array}$ & $\begin{array}{c}\text { Coruña (véase Popular) } \\
\text { Tolosa (véase Hispano) } \\
\text { Irún } \\
\text { Málaga }\end{array}$ & \\
\hline 1980 & 1985 & 1990 (BBV) $\left(^{* *}\right)$ & \\
\hline $\begin{array}{l}\text { Comercio } \\
\text { Ind. de Bilbao }\end{array}$ & $\begin{array}{l}\text { Comercio } \\
\text { Ind. de Bilbao } \\
\text { Mas Sardá }\end{array}$ & $\begin{array}{c}\text { Comercio } \\
\text { Ind. de Bilbao } \\
\text { Banca Catalana } \\
\text { Ind. Cataluña } \\
\text { Ind. Mediterráneo } \\
\text { Barcelona } \\
\text { Occidental } \\
\text { Finanzia (ex-Oeste) } \\
\text { Créd. y Ahorro } \\
\text { Créd. Canario } \\
\text { Meridional } \\
\text { Privanza (ex-Ind. Sur) } \\
\text { Extremadura }\end{array}$ & \\
\hline Huesca & $\begin{array}{c}\text { Huesca } \\
\text { Extremadura } \\
\text { Promoción Negocios } \\
\text { Oeste } \\
\text { Sindicato Banqueros }\end{array}$ & $\begin{array}{l}\text { Promoción Negocios } \\
\text { Saudí Español } \\
\text { (véase Banesto) }\end{array}$ & \\
\hline
\end{tabular}

$\left({ }^{*}\right)$ El Banco de Bilbao absorbió al Banco de Comercio en 1901, aunque lo mantuvo como entidad jurídicamente independiente. En los gráficos de Roldán, García Delgado y Muñoz (1973) para 1921 no aparece el Banco de Comercio, aunque se ha incluido en este cuadro.

$\left.{ }^{(* \star}\right)$ Según la Memoria anual, el Banco Bilbao-V izcaya poseía la mayoría de las acciones de los bancos de Comercio (100 por 100), Ind. de Bilbao (99,8 por 100), Banca Catalana (94 por 100), Ind. Cataluña (93,6 por 100), Ind. Mediterráneo (93,6 por 100), Barcelona (94 por 100), Occidental (100 por 100), Finanzia (ex-Oeste) (100 por 100), Créd. y Ahorro (100 por 100), Créd. Canario (100 por 100), Meridional (100 por 100), Privanza (ex-Ind. Sur) (100 por 100), Extremadura (100 por 100), Promoción de Negocios (99,6 por 100) y Bilbao Merchant Bank (100 por 100). 


\subsection{Relaciones del Banco de Vizcaya}

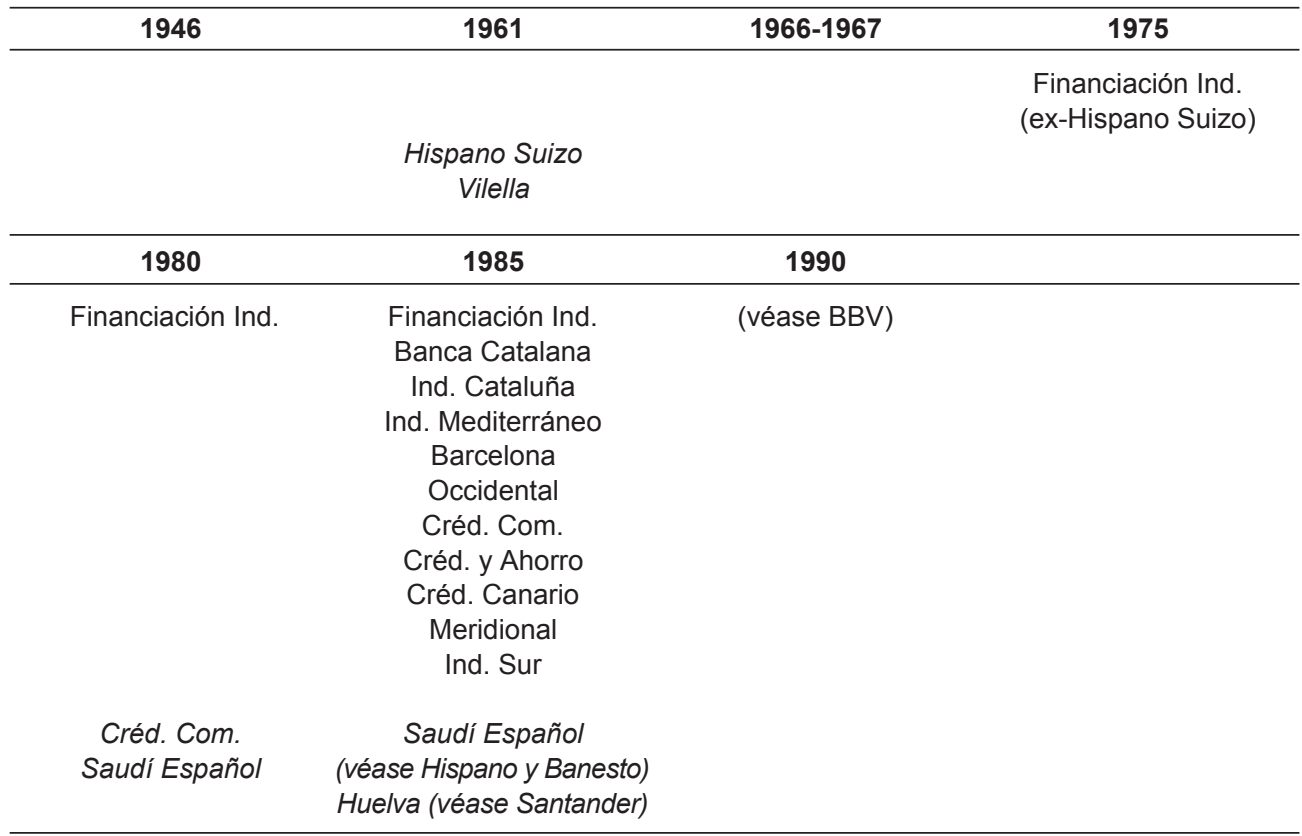

1.7. Relaciones de bancos catalanes antes de la Guerra Civil: vinculados a la Banca Arnús

\begin{tabular}{cccc}
\hline 1915 & 1921 & 1925 & 1934 \\
\hline $\begin{array}{c}\text { Créd. y Docks } \\
\text { Menorca } \\
\text { Sabadell }\end{array}$ & $\begin{array}{c}\text { Créd. y Docks } \\
\text { Menorca }\end{array}$ & (véase Central) \\
Sabadell $y$ Docks & $\begin{array}{c}\text { Cía. Créd. Bancario } \\
\text { Sindicato Banqueros }\end{array}$ & $\begin{array}{c}\text { Sabadell } \\
\text { Com. Tarrasa } \\
\text { (véase Marsans) }\end{array}$ & \\
\hline
\end{tabular}

1.8. Relaciones de bancos catalanes antes de la Guerra Civil: vinculados al Banco Hispano Colonial

\begin{tabular}{cccc}
\hline 1915 & 1921 & 1925 & 1934 \\
\hline Barcelona & Barcelona & Urquijo Catalán & \\
Arnús-Garí & Arnús-Garí & Mercantil & \\
Sindicato Banqueros & Cía. Créd. Bancario & López Bru \\
& Urquijo Catalán & Internal. Ind.y Com. & \\
& & Arnús-Garí & \\
& & & \\
& &
\end{tabular}


1.9. Relaciones de bancos catalanes antes de la Guerra Civil: vinculados al Banco de Cataluña

\begin{tabular}{|c|c|c|c|}
\hline 1915 & 1921 & 1925 & 1934 \\
\hline & Reus & Reus & \\
\hline & Tortosa & Tortosa & \\
\hline & Cía. Créd. Bancario & Com. Tarragona & \\
\hline & $\begin{array}{c}\text { Sindicato Banqueros } \\
\text { Marsans }\end{array}$ & Sindicato Banqueros & \\
\hline
\end{tabular}

1.10. Relaciones de bancos catalanes antes de la Guerra Civil: vinculados a la Banca Marsans

$\begin{array}{ccc}1915 & 1925 & 1934 \\ & \begin{array}{c}\text { Internacional Ind. y Com. } \\ \text { Com. Tarrasa }\end{array} & \begin{array}{c}\text { Internacional Ind. y Com. } \\ \text { Com. Tarrasa } \\ \text { Com. Barcelona } \\ \text { Valencia }\end{array} \\ & \text { Castellón } \\ \text { Tortosa (véase Cataluña) } & \text { Créd. y Docks (véase } & \text { Propiedad } \\ \text { Cía. Créd. Bancario } & \text { Arnús) } & \text { Sindicato Banqueros } \\ \text { Sindicato Banqueros } & \text { Prés. y Dtos.-Com. } & \\ & \text { Barcelona } \\ & \text { Arnús-Garí } & \\ & \text { Hispano Colonial } & \\ & \text { Bilbao-Comercio } & \\ & \text { Sindicato Banqueros }\end{array}$

1.11. Relaciones del Banco de Santander

\begin{tabular}{ccc}
\hline 1961 & $1966-1967$ & 1975 \\
\hline Soler y Torra & $\begin{array}{c}\text { Com. para América } \\
\text { (ex-Soler y Torra) } \\
\text { Intercontinental } \\
\text { (Bankinter) }\end{array}$ & $\begin{array}{c}\text { Com. América } \\
\text { Bankinter }\end{array}$ \\
Soler y Torra & $\begin{array}{c}\text { Sindicato Banqueros } \\
\text { (véase Banesto } \\
\text { Sindicato Banqueros } \\
\text { (véase Central) }\end{array}$ & \begin{tabular}{c} 
Central) \\
\hline
\end{tabular}
\end{tabular}




\subsection{Relaciones del Banco de Santander (cont.)}

\begin{tabular}{ccc}
\hline 1980 & 1985 & $1990\left(^{*}\right)$ \\
\hline $\begin{array}{c}\text { Bank of America } \\
\text { (ex-Com. América) } \\
\text { Bankinter }\end{array}$ & $\begin{array}{c}\text { Bankinter } \\
\text { Contander Negonocios }\end{array}$ & $\begin{array}{c}\text { Bankinter } \\
\text { Santander Negocios } \\
\text { Jover }\end{array}$ \\
$\begin{array}{c}\text { Com. Español } \\
\text { Jover }\end{array}$ & $\begin{array}{c}\text { Bank of America } \\
\text { Condal }\end{array}$ & $\begin{array}{c}\text { Condal } \\
\text { Huelva }\end{array}$ \\
& Huelva (véase Banesto & \\
& Vizcaya) \\
& Jover & \\
& & \\
&
\end{tabular}

$\left(^{*}\right)$ Según la Memoria anual del Banco Santander, éste era propietario de los bancos Santander de Negocios (100 por 100), de Murcia (100 por 100) y Jover (67 por 100).

\subsection{Relaciones del Banco Popular}

\begin{tabular}{|c|c|c|c|}
\hline 1946 & 1961 & 1966-1967 & 1975 \\
\hline \multirow[t]{2}{*}{ (véase Central) } & (véase Central) & $\begin{array}{c}\text { Andalucía } \\
\text { (véase Central) } \\
\text { Salamanca } \\
\text { Huelva } \\
\text { Europeo Negocios }\end{array}$ & Europeo Negocios \\
\hline & & $\begin{array}{c}\text { La Coruña } \\
\text { (véase Bilbao) } \\
\text { Ind. Cataluña } \\
\text { (véase Banesto } \\
\text { y Central) } \\
\text { Zaragozano } \\
\text { López Quesada } \\
\text { Central }\end{array}$ & $\begin{array}{c}\text { Créd. Balear } \\
\text { Andalucía } \\
\text { Castilla } \\
\text { Societe Generale }\end{array}$ \\
\hline 1980 & 1985 & $1990\left(^{*}\right)$ & \\
\hline $\begin{array}{c}\text { Popular Ind. } \\
\text { (ex-Europeo Negocios) }\end{array}$ & Popular Ind. & Popular Ind. & \\
\hline $\begin{array}{l}\text { Créd. Balear } \\
\text { Andalucía }\end{array}$ & $\begin{array}{c}\text { Créd. Balear } \\
\text { Andalucía } \\
\text { Exportación }\end{array}$ & $\begin{array}{l}\text { Créd. Balear } \\
\text { Andalucía }\end{array}$ & \\
\hline
\end{tabular}

$\left(^{*}\right)$ Según la Memoria anual del Banco Popular, éste era propietario de los bancos de Andalucía (61 por 100), de Castilla (90 por 100), Crédito Balear (57 por 100), de Galicia (86 por 100), V asconia (92 por 100) y Popular Industrial (98 por 100). 


\section{APÉNDICE 2}

ORGANIGRAMAS DE RELACIONES ENTRE AGRUPACIONES DE BANCOS

\subsection{Relaciones entre agrupaciones en 1921}

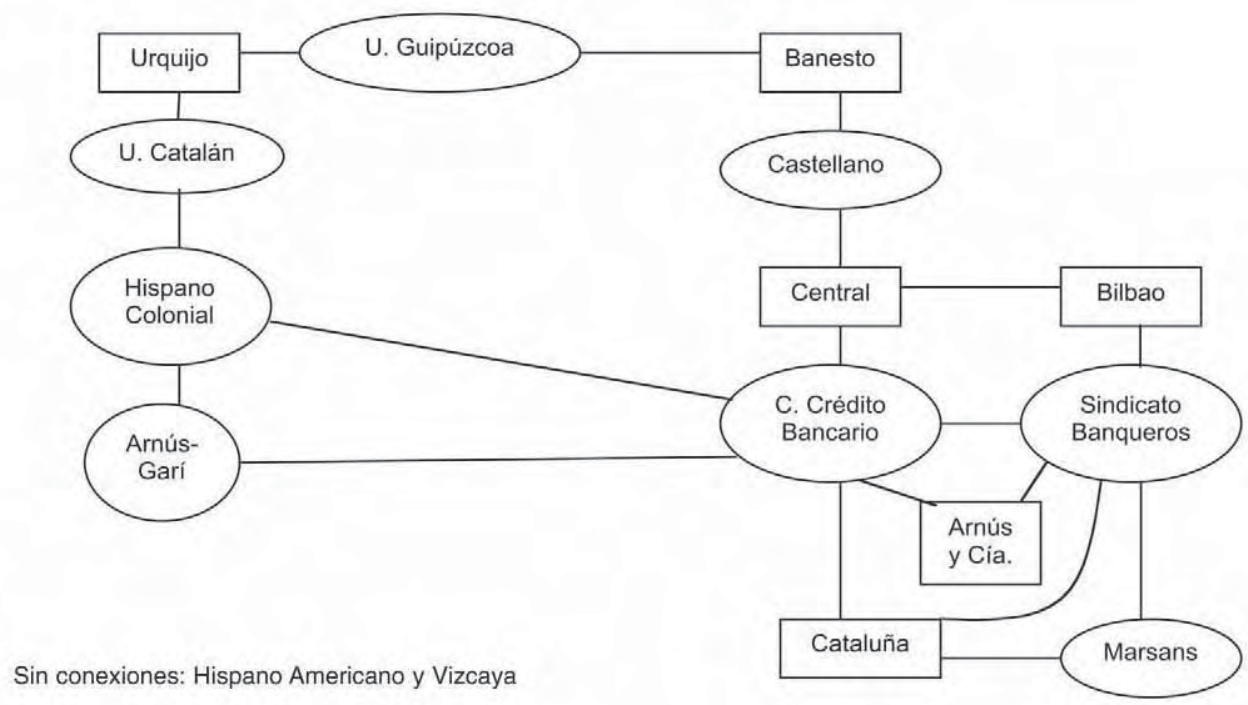

\subsection{Relaciones entre agrupaciones en 1925}

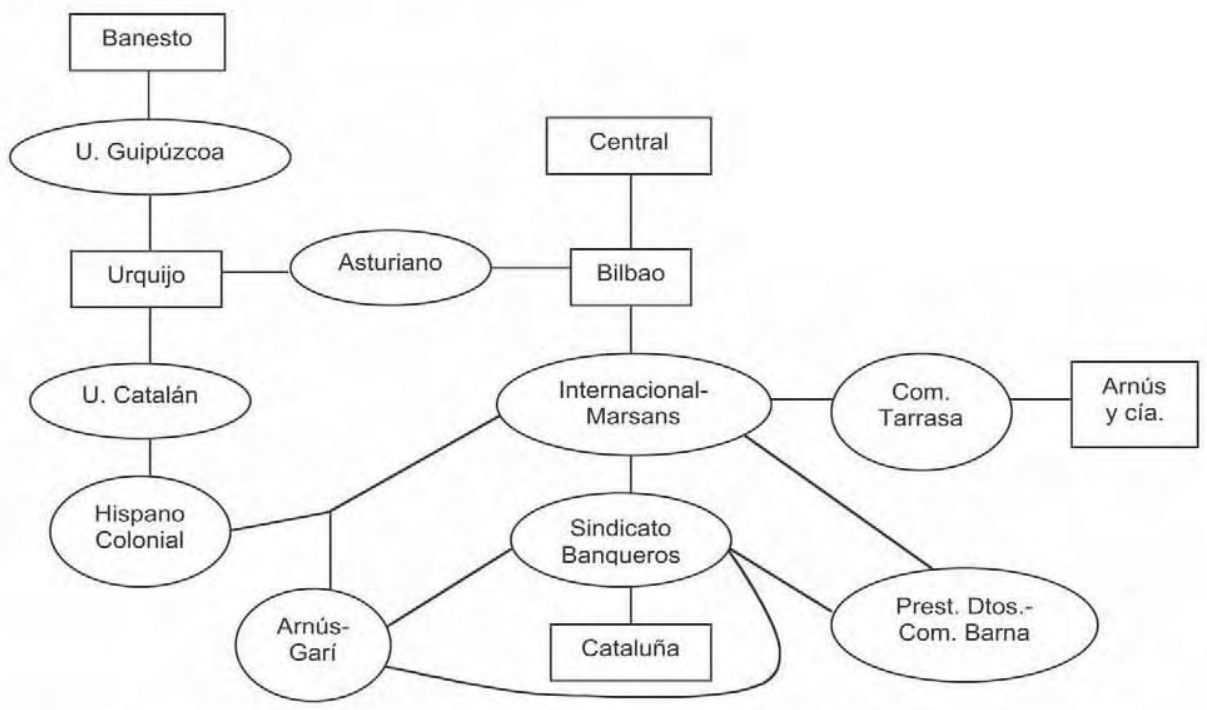

Sin conexiones: Hispano Americano y Vizcaya 


\subsection{Relaciones entre agrupaciones en 1934}

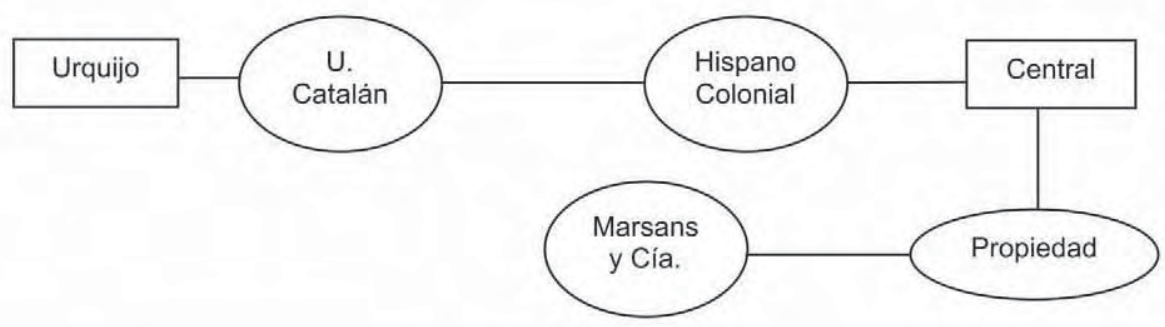

Sin conexiones: Hispano Americano, Banesto, Bilbao y Vizcaya

\subsection{Relaciones entre agrupaciones en 1946}

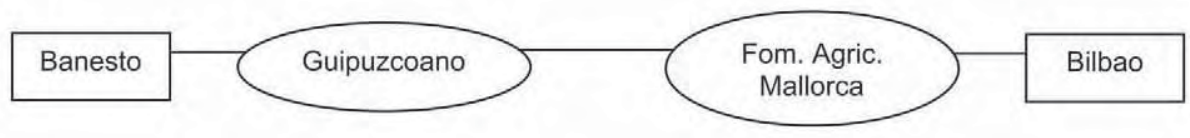

Sin conexiones: Hispano Americano, Central y Vizcaya

\subsection{Relaciones entre agrupaciones en 1961}

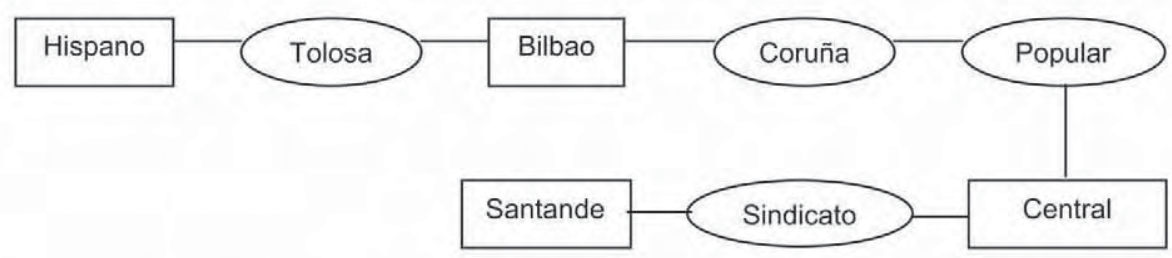

Sin conexiones: Banesto y Vizcaya 


\subsection{Relaciones entre agrupaciones en 1966-1967}

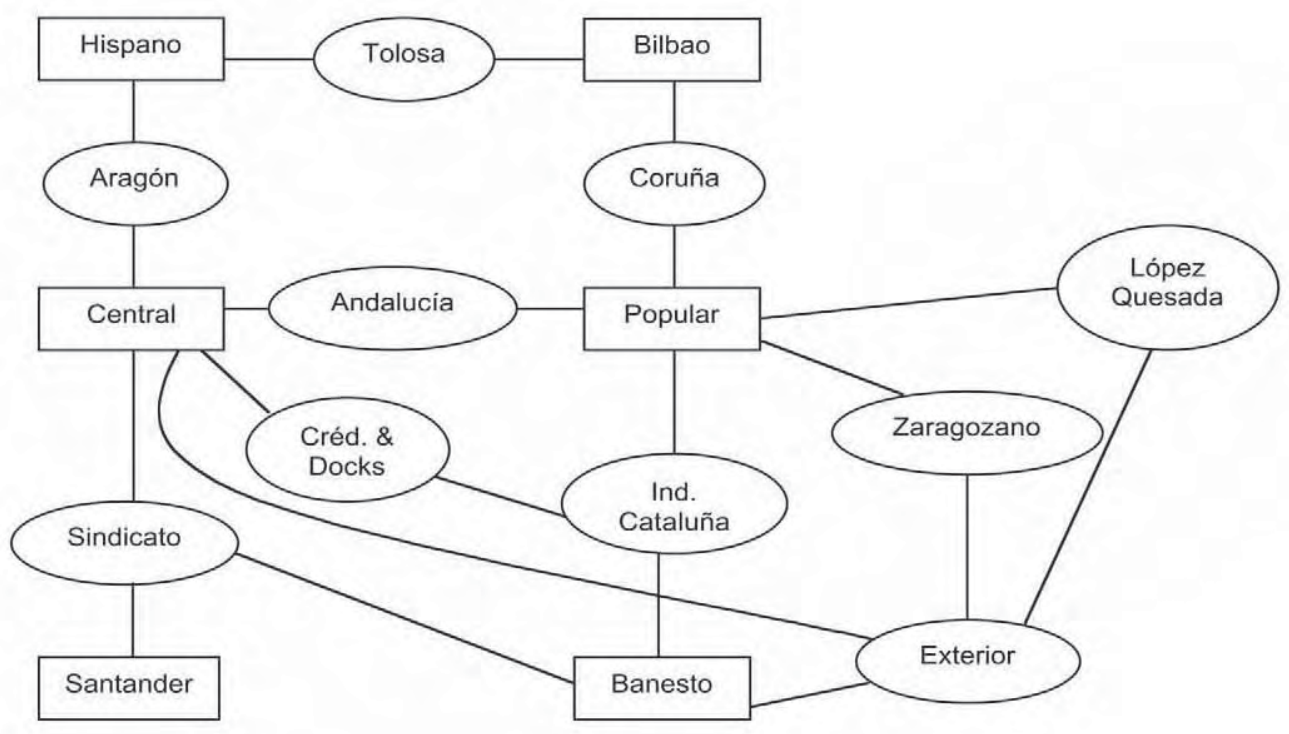

Sin conexiones: Vizcaya

\subsection{Relaciones entre agrupaciones en 1980}

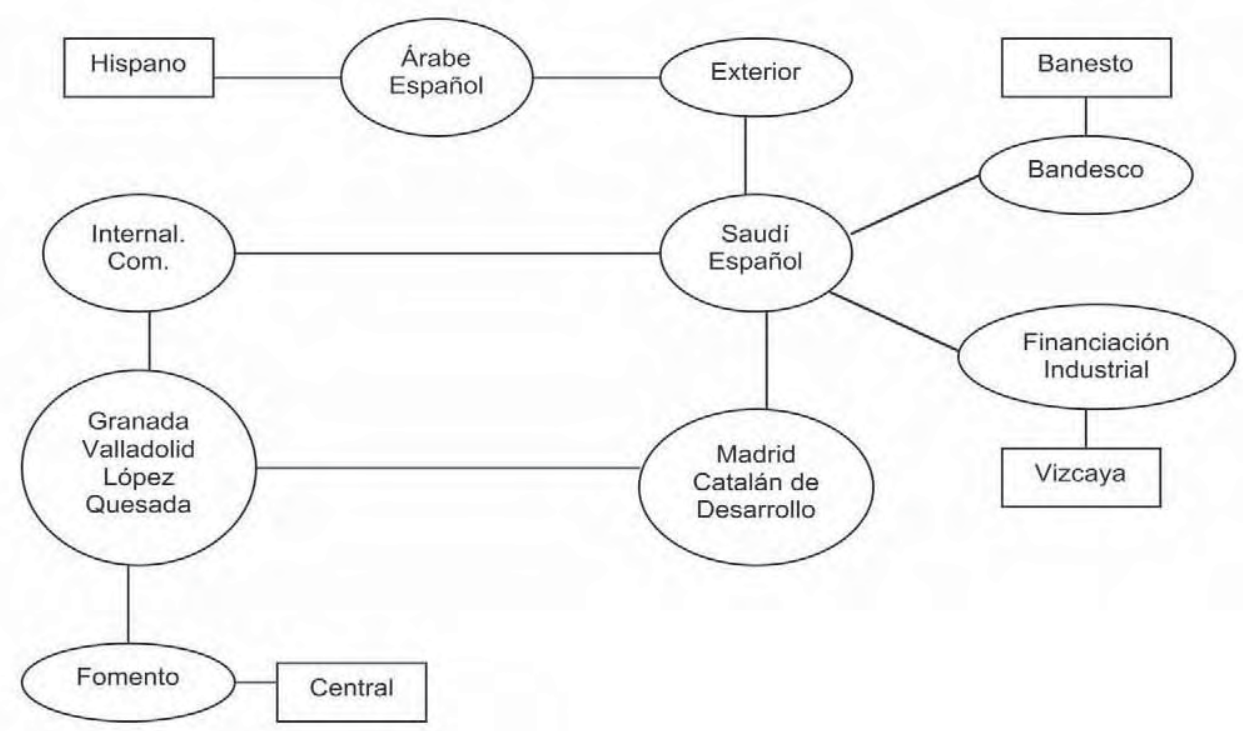

Sin conexiones: Bilbao, Santander y Popular 


\subsection{Relaciones entre agrupaciones en 1985}

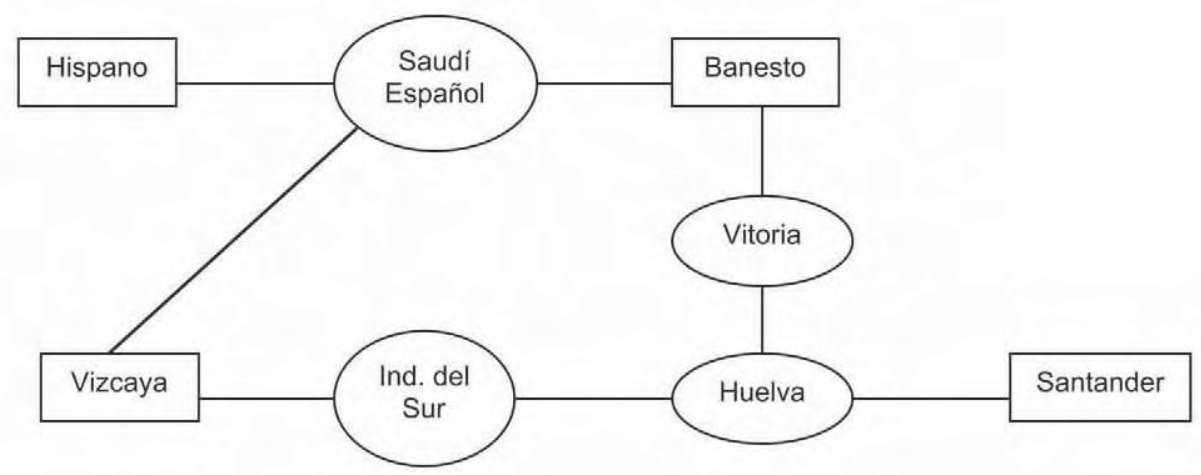

Sin conexiones: Bilbao, Central y Popular

\subsection{Relaciones entre agrupaciones en $\mathbf{1 9 9 0}$}

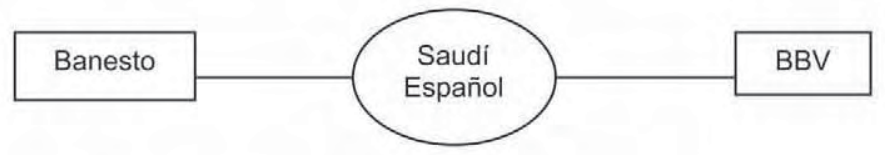

Sin conexiones: Hispano, Central, Santander y Popular 